Rossi, Rafael. A perspectiva territorial no debate das políticas públicas: Contribuições a partir da problematização geográfica. GeoGrahos. [En línea]. Alicante: Grupo Interdisciplinario de Estudios Críticos y de América Latina (GIECRYAL) de la Universidad de Alicante, 6 de enero de 2013, vol. 4, no 33, p. 34-51. [ISSN: 2173-1276].

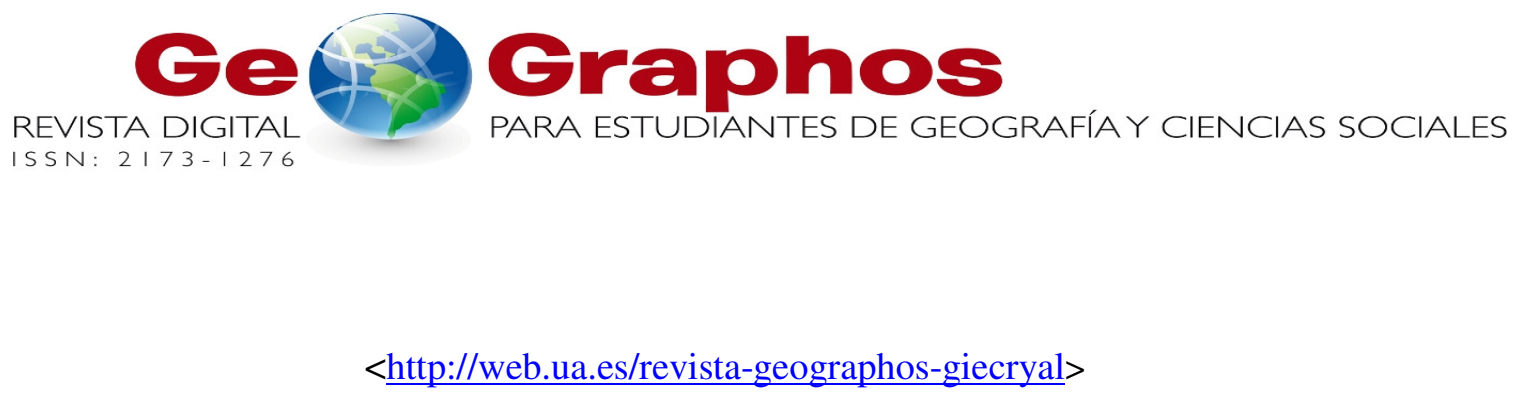

Vol. 4. $\mathrm{N}^{\mathrm{o}} 33$

Año 2013

\title{
A PERSPECTIVA TERRITORIAL NO DEBATE DAS POLÍTICAS PÚBLICAS: CONTRIBUIÇÕES A PARTIR DA PROBLEMATIZAÇÃO GEOGRÁFICA
}

\author{
Rafael Rossi \\ Mestrando em Geografia no Programa de Pós-Graduação em Geografia \\ Universidade Estadual Paulista-UNESP. Presidente Prudente, São Paulo, Brasil \\ Membro do Centro de Estudos e Mapeamento da Exclusão Social para Políticas \\ Públicas-CEMESPP. Presidente Prudente, São Paulo, Brasil \\ Correio eletrônico: rafaelrossi6789@ hotmail.com
}

Recibido: 2 de agosto de 2012. Devuelto para revisión: 30 de agosto de 2012.

Aceptado: 6 de enero de 2013

\section{RESUMO}

O conceito de território vem permeando cada vez mais as falas, documentos e legislações das políticas públicas no Brasil. Acreditamos que nesse processo a Geografia pode contribuir para evitar a despolitização desse conceito e também para aprumar esse debate com intuito de oferecer a partir de seu arsenal teórico e metodológico os caminhos para pensarmos na sua operacionalização. Assim, este texto debate os conceitos de políticas públicas e de território, com intuito de problematizar a partir da leitura Geográfica potencialidades desses vínculos e perspectivas. Este panorama configura-se em um amplo desafio à agenda acadêmica de pesquisa sobre as desigualdades sociais e igualmente às políticas públicas que pretendam combater tal 
manifestação e propagação a partir das condições reais e concretas das famílias que enfrentam tais processos.

Palavras-chave: Território, políticas públicas, territorialidade, territorialização.

\title{
LA PERSPECTIVA TERRITORIAL EM EL DEBATE DE LAS POLÍTICAS PÚBLICAS: CONTRIBUCIONES A PARTIR DE LA PROBLEMATIZACIÓN GEOGRÁFICA
}

\section{RESUMEN}

El concepto de territorio es cada vez más penetrando las declaraciones, los documentos de las leyes y políticas públicas en Brasil. Creemos que este proceso de la geografía puede ayudar a prevenir la despolitización del concepto y también para enderezar este debate con el fin de ofrecer a su arsenal de las formas teóricas y metodológicas para pensar en su funcionamiento. Por lo tanto, este documento aborda los conceptos de políticas públicas y el territorio, con el objetivo de discutir la lectura del potencial geográfico de estos enlaces y puntos de vista. En este escenario se establece un amplio desafío a la agenda de investigación académica sobre las desigualdades sociales y también a las políticas públicas que tengan la intención de luchar contra esta manifestación y propagación de las condiciones concretas reales de las familias que enfrentan estos procesos.

Palabras clave: Territorio, políticas públicas, territorialidad, territorialización.

\section{TERRITORIAL PERSPECTIVE ON PUBLIC POLICY DEBATE: CONTRIBUTIONS FROM THE GEOGRAPHICAL PROBLEMATIZATION}

\begin{abstract}
The concept of territory is increasingly permeating the statements, documents the laws and public policies in Brazil. We believe that this process geography can help to prevent the depoliticization of the concept and also to straighten this debate in order to offer their arsenal from the theoretical and methodological ways to think of its operation. Thus, this paper discusses the concepts of public policy and territory, aiming to discuss the reading from the geographic potential of these links and perspectives. This scenario sets up a broad challenge to the academic research agenda on social inequalities and also to public policies that intend to fight this manifestation and propagation from the real concrete conditions of families facing such processes.
\end{abstract}

Key words: Territory, public policy, territoriality, territorialisation.

\section{INTRODUÇÃO}

Este texto trata-se de reflexões oriundas da pesquisa que desenvolvemos no mestrado em Geografia na UNESP, Faculdade de Ciências e Tecnologia de Presidente Prudente - 
SP, intitulada: "A perspectiva territorial nas políticas públicas: Análise espacial a partir do índice de desenvolvimento das famílias em Presidente Prudente - SP". O processo de produção do espaço urbano envolve uma série de ações e agentes que resultam concretamente em situações de desigual distribuição dos bens e das riquezas. Este processo se relaciona diretamente ao modo capitalista de produção, com sua lógica de concentração e de geração estruturante das desigualdades sociais, sendo que estas, por sua vez, contribuem e se articulam ao processo de exclusão social. Este panorama configura-se em um amplo desafio à agenda acadêmica de pesquisa sobre tais desigualdades e igualmente às políticas públicas que pretendam combater tal manifestação e propagação a partir das condições reais e concretas das famílias que enfrentam tal processo.

Assim, na primeira parte iremos discutir o conceito de políticas públicas em seu desafio de combate os processos excludentes. Aproximamo-nos mais do termo "policy", como será abordado, por tratar das condições reais e concretas com que se lidam os obstáculos e estratégias de intervenção das políticas públicas. O Estado possui um papel ativo e de suma relevância na produção das desigualdades sociais e na acentuação dos processos excludentes. No entanto, em seu caráter contraditório, o Estado demanda informações e dados sociais para a intervenção, que ajudem na elaboração e implementação das políticas públicas.

Nesse processo o uso do conceito de território, que será discutido na segunda parte, a partir das contribuições oriundas da Geografia, permite problematizar tal movimento dinâmico como procedimento que pode contribuir na discussão a respeito da perspectiva territorial nas políticas públicas. O território evidencia a manifestação empírica concreta e presente em toda realidade em que podemos perceber os diversos interesses, barganhas, ambições, desejos materializados, as carências e dificuldades enfrentadas por grupos sociais que enfrentam o processo de exclusão social. Já a terceira parte reservase às nossas proposições e considerações a respeito da discussão aqui em pauta.

Vale considerar que as proposições aqui expostas sobre a perspectiva territorial no debate das políticas públicas, não pretende fechar-se hermeticamente à novas contribuições. Assim sendo, dúvidas, críticas e sugestões são bem-vindas para ampliar essas problematizações a partir do arcabouço teórico e metodológico que a Geografia oferece.

\section{CONCEITUANDO AS POLÍTICAS PÚBLICAS}

O conceito de políticas públicas consolidou-se e ganhou relevância na pauta de agenda de diversos pesquisadores: economistas, gestores públicos, geógrafos, sociólogos, cientistas políticos, urbanistas, engenheiros e agentes políticos responsáveis por tomadas de decisões. Neste sentido cabe questionarmos: Em quais contextos são elaboradas as políticas? Em contextos de homogeneidade, de harmonia e entendimento? Ou de conflitos?

Com relação à significação do termo política pública, faz-se necessário afirmar que o mesmo tem sua origem atrelada aos países de língua inglesa, sendo traduzido como public policy, vinculando ao sentido da palavra "política" em português. A literatura em 
língua inglesa diferencia a análise do estudo do fenômeno político em três diferentes dimensões. No entanto, em países de língua originaria do latim, como Brasil, Espanha, Itália, apresentam somente um tipo de tradução para o termo que é "política".

Os termos policy, polity, politics em inglês representam estes diferentes dimensões que em língua portuguesa não é possível tal diferenciação. Segundo Secchi (2010):

Policy: O termo refere-se à dimensão material, conteúdos concretos, isto é, à configuração dos programas políticos. Possuem relação com a formação de agenda para tomada de decisões e ações;

Polity: $O$ termo refere-se à dimensão institucional, a ordem do sistema político delineada pelo sistema jurídico e à estrutura institucional do sistema políticoadministrativo;

Politics: Refere-se ao quadro da dimensão processual, tem-se em vista o processo político, freqüentemente de caráter conflituoso, no que diz respeito à imposição de objetivos devido a questões políticas de tomadas de decisões e elaborações de agenda, refere-se ainda aos conteúdos e às decisões de distribuição.

Acreditamos que nossa pesquisa se relaciona ao termo "policy". Isso ocorre, visto que nosso esforço está em argumentar sobre as condições concretas da realidade social de famílias que vivenciam os processos de exclusão social.

Uma vez entendidos estes termos ${ }^{1}$ é necessário afirmar que na fase de elaboração das políticas públicas, está presente a identificação e definição do "problema" o que constitui ponto crucial e inicial de análise para o entendimento da articulação e objetivos que se pretendem materializar em uma intervenção. $\mathrm{O}$ "problema" pode ser compreendido como algo da realidade que necessita ser posicionado nas reflexões dos formuladores da política para que o foco seja delimitado e a precisão da política possa aumentar. A identificação de um problema é de suma importância, pois este irá definir o agendamento da política pública, suas normas, objetivos e metodologias, como discutidos em Secchi (2010).

Para o mesmo autor após a fase de identificação e delimitação do problema e suas possibilidades de enfrentamento, chega-se a avaliação dos recursos disponíveis destinados a política, o que implicará em ações e em decorrência a resultados sobre a efetividade da mesma.

Com relação à fase de implementação, Silva e Melo (2000) a entendem como a execução de ações com vistas a garantir a obtenção das metas decididas e pensadas no processo de elaboração da política. A implementação se baseia em uma análise prévia e com um sistema de informações com a definição não somente das metas, mas também de recursos e da duração de tempo de planejamento. Implementação, portanto, é o momento em que a ação governamental explicita e demonstra programas e projetos de intervenção.

\footnotetext{
${ }^{1}$ É possível encontrar essa discussão mais ampla em Frey (2000) e Secchi (2010).
} 
A partir da perspectiva dos autores Silva e Melo (2000), consideramos que há muito que se aprofundar no estudo da implementação de uma política, visto as suas necessidades técnicas-operacionais, além do fato de esta ser uma fase em que o conhecimento sobre o fenômeno social que se pretende intervir necessitaria ser problematizado. No tocante às características técnicas-operacionais, implantar uma política é o resultado de um processo que se inicia na delimitação de um problema a ser combatido (e/ou de acordo com as pretensões em questão, amenizado) se utilizando, em nossa compreensão, de um sistema de informações das famílias e dos locais a serem atendidos, que pontue as carências e sustente a eficácia da aplicação dos recursos, de acordo com os objetivos da política. Essa visão permite-nos apurar o olhar investigativo com relação às políticas públicas, persistindo na detecção e compreensão dos desafios e procedimentos presentes em cada fase.

Optamos por trazer à discussão a definição do Estado, para prosseguir em nossa problematização. De acordo com o Dicionário do Pensamento Marxista editado por Tom Bottomore, trata-se de um conceito de fundamental relevância para o marxismo, compreendendo sua função a fim de assegurar e conservar a dominação e exploração de classe. Para Bottomore (2001), Engels em seu livro A origem da Família, da propriedade privada e do Estado afirma que o Estado é: "em geral, o Estado da classe mais poderosa, economicamente dominante, que por meio dele, torna-se igualmente a classe politicamente dominante, adquirindo com isso novos meios de dominar e explorar a classe oprimida" (Bottomore, 2001, p. 134). Bottomore afirma:

O marxismo clássico e o leninismo sempre ressaltaram o papel coercitivo do Estado, quase que com a exclusão de todos os outros aspectos: o Estado é essencialmente a instituição pela qual uma classe dominante e exploradora impõe e defende seu poder e seus privilégios contra a classe ou classes que domina e explora (Bottomore, 2001, p. 136).

Assim, nossa compreensão de Estado não se aproxima da visão marxista clássica, apontada por Bottomore (2001), se configurando em instrumento de poder somente de uma classe social. O Estado é aqui entendido não como homogêneo e totalmente ilhado ou separado das outras esferas sociais, mas sim como espaço de barganhas, conflitos ou consensos entre diferentes grupos que se estruturam em seu interior, que podem exercer maior ou menor intervenção de acordo com cada momento histórico. Carlos (2007) afirma que no nível político, o Estado, atua na produção do espaço urbano com a criação e reforço de centralidades (como forma de dominação); com a hierarquização dos lugares (importância nas estratégias de reprodução); com a imposição de sua presença e através do controle e vigilância, por meio da mediação da norma. A mesma autora continua:

O Estado desenvolve estratégias que orientam e asseguram a reprodução das relações no espaço inteiro (elemento que se encontra na base da construção de sua nacionalidade), produzindo-o enquanto instrumento político intencionalmente organizado e manipulado. É, portanto, um meio e um poder nas mãos de uma classe dominante que diz representar a sociedade, sem abdicar de objetivos próprios de dominação, usando como meio as políticas públicas para direcionar e regularizar fluxos, centralizando, valorizando/desvalorizando os lugares através de intervenções como "ato de planejar" (Carlos, 2007, p. 52). 
Há um caráter conflituoso imanente a esse agente produtor do espaço urbano. O Estado é constituído por diferentes grupos sociais com interesses e objetivos divergentes, para garantir sua hegemonia e projetos, por isso a noção de embates na fase de elaboração das políticas públicas, como já argumentamos. Ao mesmo tempo em que contribui para a produção das desigualdades sociais e do processo de exclusão, ele gera demanda por informações que possibilitem a elaboração de políticas públicas que combatam tais processos. O trecho de Carlos (2007) se aproxima da compreensão contida em Bottomore (2001), a partir dos interesses e estratégias de manutenção dos interesses da classe dominante.

Gramsci (1976) apresenta argumentos para superar a compreensão "ingênua" de política. Para o autor entender a política de maneira superficial e corriqueira como uma política parlamentar, empobrece o conceito de Estado. Esse, por sua vez, apresenta as tramas, intrigas, jogos e relações de poder, através dos quais aqueles que estão sob sua atenção se tornam mais que dominados, mas sim uma consciência coletiva que aceita as decisões tomadas e impostas. Este autor avança no entendimento clássico de Estado do marxismo, por o entender como disputa entre classes sociais para o exercício da hegemonia $^{2}$.

Tudo que há de importante na sociologia não passa de ciência política. [...] Convencimento de que com as instituições e os parlamentos tivesse começado uma época de "evolução" "natural", que a sociedade tivesse encontrado os seus fundamentos definitivos, porque racionais, etc. Eis que a sociedade pode ser estudada pelos métodos das ciências naturais. Empobrecimento do conceito de Estado, em conseqüência de tal visão. Se ciência política significa ciência do Estado, e Estado é todo complexo de atividades práticas e teóricas com as quais a classe dirigente justifica e mantém não só o seu domínio, mas consegue obter o consentimento ativo dos governados, é evidente que todas as questões essenciais da sociologia não passam de questões da ciência política. (Gramsci, 1976, p. 87).

Gramsci (1976) entende dois grandes grupos e/ou tipos de política: a grande política e a pequena política. A primeira refere-se a questões estruturadoras de manutenção e atuação entre os Estados, já a segunda, materializa-se nas opções e escolhas, consolidadas através dos legisladores e imbuídas de interesses resultantes de embates e lutas no interior do Estado, que se realiza no cotidiano, contribuindo para a manutenção do exercício do poder.

Grande política (alta política), política menor (política do dia-a-dia, política parlamentar, de corredores, de intrigas). A grande política compreende as questões ligadas à fundação de novos Estados, com a luta pela destruição, a defesa, a conservação de determinadas estruturas orgânicas econômico-sociais. A política menor

\footnotetext{
${ }^{2}$ De acordo com Bottomore (2001) no entendimento de Gamsci, para uma classe manter seu domínio sobre as demais, além da organização da força, ela tem de avançar em estratégias que não se prendam somente em seus interesses específicos, realizando concessões e obtendo aliados unificados em um bloco histórico. Este bloco representa um consentimento para uma ordem social, onde a hegemonia da classe dominante é criada e recriada nas relações sociais e nas ideias. Dessa forma a classe hegemônica é também política, já que supera seus interesses econômicos imediatos, representando o "avanço universal da sociedade". (Bottomore, 2001, p. 178).
} 
compreende as questões parciais e quotidianas que se apresentam no interior de uma estrutura já estabelecida, em virtude de lutas pela predominância entre as diversas frações de uma mesma classe política. (Gramsci, 1976, p. 159).

O autor explicita como os interesses da classe dominante podem se manifestar em práticas organizadas e implantadas pelo Estado, com a aceitação dos governados, com intuito de prevalecer como classe hegemônica.

Parece-me que o que de mais sensato e concreto se pode dizer a propósito do Estado ético e de cultura é o seguinte: cada Estado é ético quando uma das suas funções mais importantes é a de elevar a grande massa da população a um determinado nível cultural e moral, nível (ou tipo) que corresponde às necessidades de desenvolvimento das forças produtivas e, portanto, aos interesses das classes dominantes. Neste sentido, a escola como função educativa positiva e os tribunais como função educativa repressiva e negativa são as atividades estatais mais importantes: mas, na realidade, no fim predominam uma multiplicidade de outras iniciativas e atividades chamadas privadas, que formam o aparelho da hegemonia política e cultural das classes dominantes. [...] só o grupo social que coloca o fim do Estado e de si mesmo como fim a ser alcançado, pode criar um Estado ético, tendente a eliminar as divisões internas de dominados, etc., e a criar um organismo social unitário técnico-moral. (Gramsci, 1976, p. 145).

Gramsci (1976) apresenta importante contribuição no entendimento das ações do Estado, dentre elas a política como resultado de conflitos e disputas internas entre os grupos que se estruturam em seu interior. Isso possui relação direta com a constatação de que muitos fatos e acontecimentos devem-se às estratégias e práticas consolidadas pela materialização de outros grupos, chamados de "privados" que podem vir a compor a hegemonia do Estado.

Avançando na perspectiva gramsciniana está Coutinho (1984), com a explicitação da complexidade inerente ao Estado com relação aos grupos que se estruturam em seu interior em uma série de conflitos e embates. Assim, as relações de poder entre esses grupos tornaram-se mais complexas e densas graças à formação de alianças para promover a garantia de objetivos e ambições partilhadas.

Já não existem mais, de um lado, indivíduos atomizados, puramente privados, lutando por seus interesses econômicos imediatos; e, de outro, o Estado como único representante dos interesses ditos "públicos". Surge uma complexa rede de organizações coletivas, de sujeitos políticos coletivos. O pluralismo deixa de ser um pluralismo de indivíduos atomizados para tornar-se cada vez mais um pluralismo de organismos de massa. Com isso, a esfera política se amplia além do âmbito do Estado em sentido estrito, ou seja, das burocracias ligadas aos aparelhos executivos e repressivos. Ao lado do Estado, surge o que Gramsci chamou de "sociedade civil", ou seja, o conjunto dos "aparelhos privados de hegemonia"; desse modo, Gramsci "amplia" a teoria do Estado que herdara de Marx e Lênin, nela incluindo a esfera da hegemonia e do consenso (cujo portador material é a "sociedade civil"), precisamente para dar conta dos novos fenômenos que a ampliação da democracia introduz na vida social. (Coutinho, 1984, p. 57). 
Dessa maneira, entendemos as relações de conflitos e lutas dos grupos sociais presentes no Estado e no tocante às políticas públicas, como sendo passíveis de investigação. A Geografia a partir de sua construção teórica pode ajudar no desvelar das condições espaciais concretas das famílias que serão abrangidas pelas políticas públicas. Iniciar sua discussão de maneira crítica e trabalhar por desenvolvê-lo exige uma acuidade analítica capaz de explicitar o entendimento sobre o Estado e os grupos sociais que se articulam em seu interior definindo diretrizes, metas e objetivos baseando-se em um amplo conjunto de interesses, ora confluentes ora divergentes.

A partir do conjunto de desigualdades (re) produzidas pelas contradições do modo capitalista de produção e consequentemente pelas relações sociais, as políticas públicas são os meios de o Estado intervir em questões sociais. Essa política de responsabilidade estatal deve ser apreendida no contexto político, social, cultural e econômico. Em que pese os desafios inerentes à sua formulação e implementação, as políticas públicas podem contar com a gestão de bancos de dados e indicadores sociais que fomentem análises para os gestores conhecerem melhor e de maneira mais ampla tal realidade com que lidam diariamente. A informação e o conhecimento, em nossa leitura, constituem elementos passíveis de serem incorporados no debate pelo enfrentamento de processos, como no caso desta dissertação, o de exclusão social em seus vínculos com as políticas públicas, pela Geografia.

Entendemos que o atual modo de produção - com relação à produção de bens e mercadorias, bem como, às relações sociais, valores, costumes etc. ${ }^{3}$ - do espaço urbano incorpora cada vez mais em sua lógica o acúmulo das desigualdades sociais, acentuando sobremaneira os processos excludentes. Os agentes que produzem e consomem o espaço urbano, são agentes sociais concretos e não processos aleatórios ou abstratos. Sua ação é complexa, variando de acordo com o acúmulo de capital, as necessidades - que podem mudar - de reprodução das relações de produção e dos conflitos que podem emergir, de acordo com a discussão de Corrêa (1989).

Uma consideração importante que o mesmo autor pontua, diz respeito à ação desses agentes. Essa ação se dá em um marco jurídico, que não é neutro, que reflete o interesse de um agente dominante e ainda, que permite transgressões de acordo com o interesse desses agentes. Esse processo culmina em um espaço urbano heterogêneo, com diferentes níveis de inclusão e exclusão social, daí a necessidade de consolidação de informações e dados sociais referenciados empiricamente para apreender sua conformação e estruturação, ou seja, como instrumento e estratégia que pode ajudar a revelar as condições concretas de vida das diversas famílias que consomem e produzem também o espaço urbano, com intuito de que essa discussão possa contribuir na das políticas públicas, já que estas também interferem nessa dinâmica.

Dessa forma, a análise da realidade social e concreta constitui a conformação de caminhos que podem ser analisados para a ampliação do debate das políticas públicas. No caso brasileiro, desde a consolidação do Sistema Único de Assistência Social SUAS - os sistemas socioassistenciais vêm ganhando articulações descentralizadas, participativas e de inclusão, em uma meta cheia de potencialidades de intervenção que engloba, ainda, forte enriquecimento de compreensão e análise a partir da contribuição

${ }^{3}$ Como nos lembram Damiani, Carlos e Seabra (1999). 
teórica por parte da Geografia com o conceito de território, como iremos debater a seguir, justamente porque este possui o potencial de explicitar as condições reais vividas pelas famílias alvo das políticas públicas e seus programas sociais.

\section{O CONCEITO DE TERRITÓRIO: POTENCIALIDADES PARA AS POLÍTICAS PÚBLICAS}

Neste item iremos debater alguns autores que se dedicam a analisar o conceito de território, explicitando a complexidade que se articula na meta pela sua operacionalização ao debate das políticas públicas de combate ao processo de exclusão social. Para tanto se faz necessário considerar que as proposições aqui discutidas têm por finalidade ajudar a revelar a perspectiva territorial nas políticas públicas com vistas à ampliação dos conhecimentos e informações necessárias que ajudem a transformar os dados e estatísticas sobre a realidade social em instrumentos de ação, possibilitando a ampliação da análise dessa discussão. A realidade em sua complexidade demonstra singularidades em cada territorialização efetivada por um indivíduo ou grupo, sendo que a perspectiva territorial nas políticas públicas abrange a discussão sobre os procedimentos envolvidos no processo de reconhecimento contínuo do território que estas ajudam a produzir.

De acordo com o Dictionary of Human Geography editado por Derek Gregory, Ron Johnston, Geraldine Pratt, Michael Watts e Sarah Whatmore (2009) o território é:

Uma unidade de espaço contíguo que é utilizado, organizado e gerido por um grupo social, indivíduo ou instituição para restringir e controlar o acesso a pessoas e lugares. Embora às vezes usado como sinônimo de lugar ou espaço, o território nunca foi um termo primordial da terminologia geográfica. O uso dominante tem sido político, envolvendo o poder de limitar o acesso a certos lugares ou regiões, ou ainda, no sentido etológico com o domínio exercido ao longo de um espaço por uma dada espécie ou um organismo. Cada vez mais, o conceito de território atrela-se ao conceito de rede, com intuito de ajudar na compreensão de processos complexos onde o espaço é gerido e controlado por organizações poderosas. (Gegory et al, 2009, p. 746, tradução nossa).

Uma primeira definição de território com base nesse dicionário indica o controle exercido por um e/ou mais grupos, remetendo-nos à restrição de acesso, ou seja, um comando que ora proíbe, ora permite. No entendimento desse conceito se inserem as influências e intervenções ocasionadas por alianças e/ou conflitos entre grupos sociais com o objetivo de territorializar suas lógicas e garantir seus objetivos e interesses. Por isso mesmo, pensar em território implica pensar em interesses materializados, em influências, em estratégias, de maneira mais ampla, se trata de pensar em exercício de poder.

Utilizando o mesmo dicionário, territorialidade pode ser entendida como: "Tanto a organização e o exercício de poder, legítimo ou não, sobre blocos de espaço ou a organização de pessoas e coisas em áreas discretas por meio do uso de limites" (Gregory et al, 2009, p. 744, tradução nossa). Avançando na leitura temos que territorialização é: 
Um processo dinâmico pelo qual seres humanos são fixados territorialmente no espaço, por uma série de atores, mas principalmente pelo Estado. A desterritorialização significa uma tendência para os Estados, no capitalismo global, para encorajar o encontro e o desenraizamento de pessoas e coisas com enormes conseqüências psicológicas e políticas. Reterritorialização é o reverso desse processo. (Gregory et al, 2009, p.745, tradução nossa)

Perante a análise dessas definições de território e territorialidade, fica claro um componente essencial em sua estrutura: o poder. Assim, falar em território sem realçar as manifestações e interesses envolvidos em sua estrutura constitui uma visão insuficiente e prematura que aos poucos contribui para a despolitização desse conceito. No tocante ao fomento de ações que fortaleçam o debate a respeito da territorialidade das políticas públicas, começamos a perceber a necessidade de compreensão do exercício de poder que constantemente está em movimento na realidade social.

Para Raffestin (1993) o território é composto por três elementos básicos: as malhas ou tecidos, os nós e as redes, sendo que o controle sobre tais elementos varia com relação ao período histórico que estivermos analisando. A territorialidade é desenvolvida por Raffestin, que irá colocá-la no centro das relações na sociedade, para tanto argumenta:

(...) a vida é constituída por relações, e daí a territorialidade pode ser definida como um conjunto de relações que se originam num sistema sociedade-espaço-tempo em vias de atingir a maior autonomia possível, compatível com os recursos do sistema. (Raffestin, 1993, p.161).

A respeito da territorialidade, a visão do autor aqui explicitada chama a atenção para sua inserção em um contexto delimitado espaço-temporalmente, porém alguns pontos de reflexão são relevantes de salientar: se a territorialidade é entendida como um conjunto de relações cujo objetivo é a maximização de sua autonomia, entendemos que os territórios estão em níveis diferentes de desenvolvimento, ou seja, uns estão mais consolidados que outros, em face da sua produção e como ela se deu naquele espaço e naquele tempo. O mesmo autor conclui: o território "é um trunfo particular, recurso e entrave, continente e conteúdo, tudo ao mesmo tempo. O território é o espaço político por excelência, o campo da ação do poder" (Raffestin, 1993, p. 60). A perspectiva abordada por Raffestin coloca e compreende a territorialidade, portanto, como as relações de dinamicidade pelo qual se exerce o poder constituindo e originando o território.

No tocante à Geografia, território e territorialidade se relacionam e são analisados a partir da materialidade do território. Esta visão nos aproxima do debate das políticas públicas, em que acreditamos estar mais próxima de um entendimento de "policy" em nossa pesquisa, justamente por tratar das condições reais e concretas da realidade de famílias em processo de exclusão social. Tal argumento também pode ser aplicado ao conceito de território, isto é, acreditamos nas potencialidades de organização das informações que trabalhem com as condições vividas materializadas na realidade para compreender e ampliar o debate sobre a perspectiva territorial nas políticas públicas, em especial as de combate à pobreza e miséria. 
Para Saquet et al (2004) entende:

O território é produzido espaço-temporalmente pelas relações de poder engendradas por um determinado grupo social. Dessa forma, pode ser temporário ou permanente e se efetiva em diferentes escalas, portanto, não apenas naquela convencionalmente conhecida como o "território nacional" sob gestão do Estado-Nação (Saquet et al, 2004, p. 10).

Saquet (2004) aponta para a superação do entendimento de território somente como o "território nacional". O autor coloca a territorialidade como prática imanente a um grupo específico em um lugar e tempo delimitados, porém o que chamamos a atenção é para o fato de essa lógica contribui para organizar e reorganizar localizações, padrões, tendências e, em especial, interações, pois como já abordamos, as redes são características para a conformação e discussão sobre os territórios.

Podemos perceber até o momento o caráter dinâmico do território, a esse respeito Brighenti (2010) argumenta que para iniciar a discussão sobre uma ciência do território - "territoriologia" - numa visão geográfica, comportamental e política alguns pontos devem ser lembrados. Em primeiro lugar, através da análise das relações entre os diversos agentes sociais se torna possível compreender os territórios superpostos que estão de vários modos conectados. Em segundo lugar, o território é uma entidade imaginada (não imaginária). E por fim, territórios têm ao mesmo tempo componentes expressivos e funcionais. A expressividade pode ser percebida na emergência de um território, com sua demarcação; já o aspecto funcional relaciona-se às estratégias e práticas inseridas na territorialidade.

Com respeito à demarcação e controle no território um escritor que trazemos para a discussão é Sack (1986). Para este o território é construído socialmente, dependendo de quem o está controlando e com qual finalidade. Nessa linha de pensamento, o território pode ser usado para restringir ou excluir pessoas, assim, para haver um território precisa-se delimitar uma área, ter alguém no comando, no controle e com isso uma forma de poder.

Territórios são os resultados de estratégias para afetar, influenciar e controlar pessoas, fenômenos e relações. É uma estratégia para estabelecer graus diferentes de acesso às pessoas, coisas e relações. (Sack, 1986, p. 19-20, tradução nossa).

Como ocorrem tais "estratégias para afetar, influenciar e controlar"? Sack (1986) entende que os limites do território podem sofrer mudanças, que se relacionam diretamente às estratégias de controle e delimitação do espaço e irá explicar tal dinâmica, a partir do conceito de territorialidade, argumentando:

Territorialidade para humanos é uma poderosa estratégia geográfica para controlar pessoas e coisas, através do controle da área. Territorialidade é uma primária expressão geográfica de poder social. São os meios pelos quais sociedade e espaço estão interrelacionados (Sack, 1986, p. 5, tradução nossa). 
Dessa forma, para Sack a territorialidade envolve uma classificação por área, que por sua vez, contém uma comunicação e de maneira enfática tem por princípio norteador o controle, ora restringindo o acesso, ora permitindo o mesmo.

Através da leitura dos diversos autores aqui abordados, entendemos que os estudos que se predispõem a compreender o conceito de território, apresentam alguns elementos para o seu debate: a atuação dos agentes, grupos, instituições e organizações que manifestam suas estratégicas e práticas territoriais nas mais diversas escalas, afim de que as disputas, as relações, as influências, a formação histórica, a demarcação (por vezes não física), as fronteiras (nem sempre fixas e intransponíveis) possam ser reveladas e, com isso, subsidiar análises e pesquisas que desvendem o ordenamento, as tendências, padrões, (des) continuidades, fragmentações, formas e conteúdos dos territórios. A territorialidade passa a ser compreendida como sendo os processos e mecanismos que garantem a efetividade dessa dinâmica. A análise da materialidade concreta e vivida, também aparece como fator passível de ser incorporado e refletido pela análise geográfica.

Nesse caminho, Castro (2003) aponta argumentos sobre as lógicas que impulsionam a distribuição espacial das riquezas e de seus benefícios, sendo posta em movimento de maneira desigual. A suposição da autora se baseia no fato de que estas diferenças se originam de condições institucionais materializadas no território, que por sua vez, afetam o exercício da cidadania.

Nas democracias contemporâneas, de países ricos ou pobres, em que esses direitos (sociais e políticos) estão estabelecidos, as possibilidades de usufruí-los dependem do conjunto de instituições que, organizadas no território, garantem a todos os habitantes o acesso a eles. É justamente esta rede institucional que constitui um dos diferenciais da cidadania naqueles dois grupos de países. Se nos países ricos, o poder infra-estrutural do Estado permite o acesso aos direitos em qualquer parte do território, num país como o Brasil a localização pode constituir um facilitador ou uma dificuldade ao exercício desses direitos (Castro, 2003, p.12).

O ponto de partida de Castro (2003) e que consideramos relevante tratar, se baseia no arranjo territorial das instituições estatais e em como estas devem garantir o acesso a todos os habitantes, se constituindo como "um facilitador ou uma dificuldade ao exercício desses direitos".

Para Yazbek (2010) o território também é terreno das políticas públicas, sendo a arena em que se concretizam os tensionamentos e os enfrentamentos, incluindo as potencialidades de ação. Para a autora, a dimensão territorial nas políticas públicas leva em consideração múltiplos fatores: sociais, econômicos, políticos e culturais que fazem com que segmentos sociais e famílias se encontrem em situação de vulnerabilidade e risco social, sendo que a visão do Sistema Único de Assistência Social - SUAS- baseiase no princípio de territorialização, numa perspectiva de proximidade do cidadão, contribuindo para identificar territórios vulneráveis e que sofrem a exclusão social, a serem priorizados. Podemos compreender, nessa discussão que os CRAS, baseados no princípio de territorialização do SUAS, na visão de Yazbek (2010) constituem-se em um equipamento pleno de possibilidades em suscitar análises e ações das políticas 
públicas, pois pelo viés da proximidade com a população pode vir a ser um "facilitador ao exercício dos direitos", parafraseando Castro (2003).

Nesse sentido, de acordo com a Política Nacional de Assistência Social (PNAS) de 2004, considerando a alta densidade populacional do país e o "alto grau de heterogeneidade e desigualdades socioterritorial presente entre os seus 5.561 municípios" a "vertente territorial se faz urgente e necessária na Política Nacional de Assistência Social" (PNAS, 2004, p. 43). Tendo nesse entendimento forte influencia de expoentes como Milton Santos, o princípio de territorialização se atrela à descentralização implementada em que se compreende o espaço urbano enquanto espaço vivo, produzido pelos diversos e numerosos agentes que o consomem e o vivenciam.

[...] Considerando que muitos dos resultados das ações da política de assistência social impactam em outras políticas sociais e vice-versa, é imperioso construir ações territorialmente definidas, juntamente com essas políticas. Importantes conceitos no campo da descentralização foram incorporados a partir da leitura territorial como expressão do conjunto de relações, condições e acessos inaugurados pelas análises de Milton Santos, que interpreta a cidade com significado vivo a partir dos "atores que dele se utilizam". (PNAS, 2004, p. 43).

Percebemos que a necessidade de "ações territorialmente definidas" se articula com a descentralização política e administrativa da política de assistência social. A "leitura territorial" atrela-se aos "atores que dele se utilizam", portanto, como proceder? Quais estratégias investigativas a serem usadas? De acordo com o documento da Política Nacional de 2004, três pressupostos aparecem como elementos que ajudam a responder tais perguntas: a territorialização, a descentralização e a intersetorialidade. O pressuposto da territorialização aproxima-se da visão de Milton Santos, como já apontamos, em que há a necessidade da "leitura territorial" a partir de quem se utiliza dos equipamentos e serviços das políticas públicas. Já os pressupostos de descentralização e intersetorialidade:

[...] Cabe a cada esfera de governo, em seu âmbito de atuação, respeitando os princípios e diretrizes estabelecidos na Política Nacional de Assistência Social, coordenar, formular e co-financiar, além de monitorar, avaliar, capacitar e sistematizar as informações [...] Dessa forma, uma maior descentralização, que recorte regiões homogêneas, costuma ser pré-requisito para ações integradas na perspectiva da intersetorialidade. Descentralização efetiva com transferência de poder de decisão, de competências e de recursos, e com autonomia das administrações dos microespaços na elaboração de diagnósticos sociais, diretrizes, metodologias, formulação, implementação, execução, monitoramento, avaliação e sistema de informação das ações definidas, com garantias de canais de participação local. Pois, esse processo ganha consistência quando a população assume papel ativo na reestruturação. [...] Torna-se necessário, constituir uma forma organizacional mais dinâmica, articulando as diversas instituições envolvidas. (PNAS, 2004, p. 44-45).

Observa-se o caráter de autonomia de gestão presente na noção de descentralização e de articulação entre instituições que compõem a rede das políticas públicas, no que diz respeito à intersetorialidade. Nesse sentido, percebe-se que os conceitos de território e 
de territorialização estão em pauta na agenda das PNAS e sua descentralização proposta por meio dos CRAS.

De acordo com Pereira (2010) na IV Conferência Nacional de Assistência Social (2003) o território é "de fato, proposto como categoria de implantação e de análise da política" (PEREIRA, 2010, p. 196). A respeito da mesma discussão, na exposição de Santos e Barros (2011):

Com a Política Nacional de Assistência Social de 2004 - PNAS 2004, o tratamento relativo a território adquiriu um outro status e a perspectiva socitoterritorial passou a ser assumida como um dos eixos estruturantes incorporados a essa política pública. Em decorrência dessa definição, foram concebidos os Centros de Referência de Assistência Social, situados nos territórios [...] (Santos e Barros, 2011, p. 2).

Dessa maneira o conceito de território passa a ter destaque no debate da PNAS, tendo nos CRAS um entendimento em que este é compreendido enquanto equipamento público que se localiza nos territórios. De acordo com essa política:

O princípio da territorialização significa o reconhecimento da presença de múltiplos fatores sociais e econômicos, que levam o indivíduo e a família a uma situação de vulnerabilidade, risco pessoal e social. O princípio da territorialização possibilita orientar a proteção social de Assistência Social:

- Na perspectiva do alcance de universalidade de cobertura entre indivíduos e famílias, sob situações similares de risco e vulnerabilidade.

- $\quad$ Na aplicação do princípio de prevenção e proteção pró-ativa, nas ações de Assistência Social.

- No planejamento da localização da rede de serviços, a partir dos territórios de maior incidência de vulnerabilidade e riscos. (PNAS, 2004, p. 19).

[...] territorialização da rede de Assistência Social sob os critérios de: oferta capilar de serviços, baseada na lógica da proximidade do cotidiano de vida do cidadão; localização dos serviços para desenvolver seu caráter educativo e preventivo nos territórios com maior incidência de população em vulnerabilidades e riscos sociais (PNAS, 2004, p. 27).

Percebemos que na concepção de território da PNAS há o reconhecimento da multidimensionalidade de fatores que conformam as situações e processos de desigualdades sociais nas famílias, a consideração da necessidade de serviços públicos na escala intra-urbana a partir da "oferta capilar" e a proximidade dos cidadãos. Nesse quesito de proximidade, Santos e Barros (2011) argumentam que os CRAS constituemse em expressões concretas do princípio de territorialização implementado pela PNAS. No entanto ao realizar recortes territoriais no processo de implantação dos CRAS, entendemos que tal fato simplifica o entendimento do conceito de território, visto que delimitar uma porção no espaço, não é o mesmo que construir ou criar um território. 
Nesse aspecto reside nossa crítica, isto é, na necessidade de superar uma visão areal como sinônimo de território. Por isso, preferimos denominar de áreas de atuação dos CRAS ao invés de "territórios". Também acreditamos, em função do estudo dos autores aqui debatidos e de nossa experiência oriunda da ida à campo, que o fato de delimitar uma área a ser atendida com base nas características das famílias, ainda é insuficiente na dinâmica de reconhecer a complexidade e abrangência do território em que residem tais grupos sociais. Aí aparece necessidade de incorporar nesse debate o procedimento de investigar continuamente tal território, para que o trabalho desenvolvido pelos profissionais nos CRAS não resumam tais populações em uma visão meramente quantitativa.

Acreditamos que os profissionais que desempenham suas funções no CRAS dispõem da potencialidade em compreender de modo mais profundo a realidade social dos territórios das famílias que vivenciam a exclusão. Assim sendo, apreendendo as práticas territoriais presentes nas áreas de atuação dos CRAS, trabalhando as informações e dados de vários órgãos de pesquisa, conhecendo e mantendo o contato direto com a população atendida, divulgando suas atividades e projetos (em um fluxo horizontal de disseminação da informação) e investindo no diálogo com diversos profissionais que se preocupam em estudar e analisar as desigualdades socioespaciais e os processos de exclusão, as possibilidades de ampliação do debate a respeito da perspectiva territorial das políticas públicas aumentam, inclusive no que se refere às "ações territorialmente definidas" (PNAS, 2004, p. 43).

Souza (2002) avança no que diz respeito ao desafio encontrado nos equipamentos públicos e de planejamento. Sua contribuição coloca em pauta o caráter participativo, de inclusão.

Sob um ângulo autonomista, os instrumentos de planejamento, por mais relevantes e criativos que sejam, só adquirem verdadeira importância ao terem a sua operacionalização (regulamentação) e a sua implementação influenciadas e monitoradas pelos cidadãos. Caso contrário corre-se o risco de atribuir aos instrumentos, em si mesmos, a responsabilidade de instaurarem maior justiça social, independentemente das relações de poder e de quem esteja decidindo, na prática, sobre os fins do planejamento e da gestão da cidade. (Souza, 2002, p. 321).

A afirmação de Souza (2002) contribui para a reflexão acerca do papel e da gestão dos serviços e equipamentos públicos na cidade, sob uma perspectiva de democracia, em que os cidadãos possuem papel ativo na gerência e acompanhamento destes, sendo mais um elemento a ser refletido pela gestão pública na escala intra-urbana.

O exercício do controle, apontado por Sack (1986), pode ser aprendido nos CRAS uma vez que estes trabalham com segmentos da população referenciados no CadÚnico da Assistência Social, como forma e estratégia de desenvolver de maneira mais prática o acompanhamento das famílias e também em uma prerrogativa de identificar aqueles que podem participar e se inserir em alguma política pública e seus programas, ou seja, o controle se manifesta através das famílias já cadastradas e referenciadas, mas também naquelas em ainda não participam de alguma ação de combate às desigualdades sociais, implicando em uma busca em identificar tais grupos sociais. 
Outros elementos e características do conceito de território podem ser problematizados tendo como referencia os CRAS, como por exemplo: as malhas, os tecidos e os nós de Raffestin (1993). O próprio CRAS se constitui em um "nó" enquanto equipamento público localizado em um território (em produção historicamente e por diversos agentes, dentre eles o Estado) em que as famílias estão submetidas aos processos excludentes. As "malhas", por sua vez, podem ser entendidas através do trabalho de articulação e de intersetorialidade (como apontado na PNAS/2004) na disseminação de informações e dados sobre os territórios, envolvendo várias instituições, ou vários "nós territoriais". Os "tecidos" constituem-se em estratégias e intervenções e confluem-se em materializações concretas das políticas públicas em seu processo de implementação e territorialização, apontando desafios, obstáculos e potencialidades à elaboração de novas ações. Assim nos CRAS a perspectiva territorial a partir da busca pela análise do território real e concreto, encontra neste equipamento público, possibilidades de se ampliar e efetivar, tendo a Geografia arsenal técnico-metodológico de investigação e reflexão que permite nos debruçar sobre essa temática.

\section{CONSIDERAÇÕES FINAIS A RESPEITO DO DEBATE TERRITORIAL NAS POLÍTICAS PÚBLICAS A PARTIR DA LEITURA GEOGRÁFICA}

O desafio que se coloca e que podemos observar dá-se de maneira territorial, ou melhor, territorializada; visto que entendemos as ações e mecanismos de vigilância, proteção e busca (elencados pela Secretária da Assistência Social) como estratégias de territorialização da política pública, que de diversas e múltiplas atividades e mecanismos pretende combater o processo de exclusão social, a partir de uma articulação com outras áreas de intervenção pública e não somente a partir da Assistência Social.

Partindo desse ponto de vista, o território necessariamente implica em relações de poder, em organização, em disputa, em grupos, em tendências, em redes e conexões, e em especial, em força e disposição para combater outras territorialidades. Devemos realizar um esforço de retornar ao território, visto que este é o elemento basilar da prática política, onde se percebem interesses coletivos, pertencimentos e a mobilização de forças para promoção da mudança: "O território significa, portanto, uma marca e uma matriz daquilo que verdadeiramente somos e do que queremos para as novas gerações de cidadãos" (Barbosa, 2010); parafraseando o mesmo autor: "o território é uma dimensão política do ser-no-mundo".

A articulação dos princípios de intersetorialidade, descentralização e territorialização condizente com cada território. Isso ocorre, pois cada um destes possui necessidades específicas, que variam de uma para outra, embora em todas as aqui discutidas esteja presente o processo de exclusão social. Dessa maneira, um território pode necessitar uma articulação intersetorial entre os serviços oferecidos pela Secretaria de Educação e a da Saúde, sendo que outro pode necessitar de uma articulação entre a Assistência Social e a Secretaria de Planejamento. Tal compreensão se estrutura a partir do conceito de território, ou seja, a perspectiva territorial nas políticas públicas possibilita problematizar uma articulação específica em cada território que se pretende intervir, justamente em decorrência desse procedimento investigativo, se encontra a necessidade 
em conhecê-lo, para avançar também em uma intervenção multidimensional referenciada territorialmente.

\section{BIBLIOGRAFIA}

BOTTOMORE, T. Dicionário do Pensamento Marxista. Rio de Janeiro: Jorge Zahar, 2001.

BRIGHENTI, A. M. On territoriology: Towards a general science of territory. Theory, Culture and Society, 2010, vol. 27, $\mathrm{n}^{\mathrm{o}}$ 1, p. 52-72.

CARLOS, A. F. A. Diferenciação Socioespacial. In: Revista Cidades, v.4, n.6, p. 50-72, 2007.

CASTRO, I. E. Instituições e território. Possibilidades e limites ao exercício da cidadania. Rev. Geosul, 2003, vol. 18, n 36, p.7-28.

COUTINHO, C. N. A Democracia como valor universal e outros ensaios. Rio de Janeiro: Salamandra, 1984.

CORRÊA, R. L. O Espaço Urbano. São Paulo: Bom Livro, 1989.

GRAMSCI, A. Maquiavel, a Política e o Estado Moderno. Rio de Janeiro: Civilização Brasileira, 1976.

GREGORY, D. et al. The Dictionary of Human Geography. 5a Ed. London: Blackwell Publishing, 2009.

PEREIRA, T. D. Política Nacional de Assistência Social e território: enigmas do caminho. Rev. Katál, 2010, vol. 3, nº 2, p.191-200.

RAFFESTIN, C. Por uma Geografia do Poder. São Paulo: Ática, 1993.

SACK, R. D. The Human Territoriality: Its theory and history. Cambridge: Cambridge University Press, 1986.

SAQUET, M. A., SPOSITO, E. S. e RIBAS, DOMINGUES, A. (Orgs). Território e desenvolvimento: diferentes abordagens. $3^{\mathrm{a}}$ ed. Francisco Beltrão/PR: UNIOESTE, v. $1000,2004.172 \mathrm{p}$.

SECCHI, L. Políticas Públicas: Conceitos, esquemas de analise, casos práticos. Cengage Learning, 2010.

SOUZA, M. L. Mudar a Cidade, uma introdução crítica ao planejamento e à gestão urbanos, Rio de Janeiro: Bertand Brasil, 2002.

YASBEK, C. et al. O sistema único de Assistência Social no Brasil: uma realidade em movimento. São Paulo: Editora Cortez, 2010. 


\section{FONTES ELETRÔNICAS UTILIZADAS}

BARBOSA, J. L. Cidade e Território: desafios da reinvenção política do espaço público. 2010. Disponível em:

$<$ http://www.observatoriodefavelas.org.br/observatoriodefavelas/acervo/view_text.php? id_text=18>. [Último acesso em 08 de Agosto de 2011.1 p.].

BRASIL. Política Nacional de Assistência Social. 2004. Disponível em:

$<$ http://www.sedest.df.gov.br/sites/300/382/00000877.pdf >. [Último acesso em: Agosto de 2012.59 p.].

SANTOS, M. M. S. e BARROS, S. A. Política Nacional de Assistência Social: impasses e desafios postos pela perspectiva socioterritorial e suas expressões nos Centros de Referência de Assistência Social - CRAS. Anais da V - Jornada Internacional de Políticas Públicas, Universidade Federal do Maranhão, de 23 a 26 de Agosto de 2011, p. 01-08. Disponível em:

<http://www.joinpp.ufma.br/jornadas/joinpp2011/CdVjornada/JORNADA_EIXO_2011 /POLITICAS_PUBLICAS_PARA_OS_TERRITORIOS_POVOS_E_COMUNIDADE S_TRADICIONAIS/POLITICA_NACIONAL_DE_ASSISTENCIA_SOCIAL.pdf $>$. [Último acesso: Agosto de 2012].

SILVA, P. L. B. e MELO, M. A. B. O processo de implementação de políticas públicas no Brasil: Características e determinantes da avaliação de Programas e Projetos. Universidade Estadual de Campinas, Caderno no 48, p. 1-17, 2000. Disponível em: $<$ http://www.nepp.unicamp.br>. [Último acesso em 10 de Julho de 2011].

CC Copyright Rafael Rossi, 2013.

(C) Copyright GeoGraphos. Revista Digital para Estudiantes de Geografía y Ciencias Sociales, 2013.

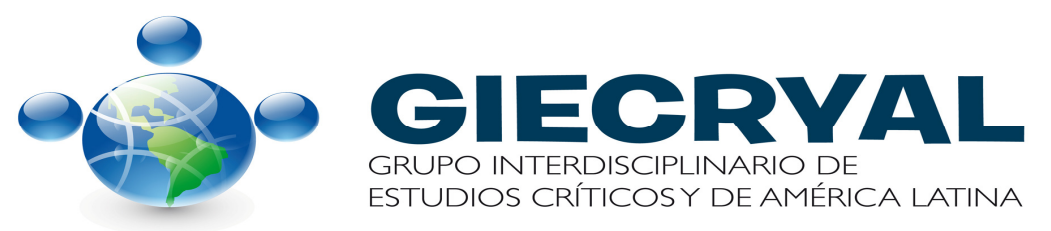

